\title{
DA (IN)APLICABILIDADE DO DIREITO FUNDAMENTAL À EDUCAÇÃO INFANTIL DE QUALIDADE ${ }^{1}$
}

Antonella Marques Neves ${ }^{2}$

\begin{abstract}
Resumo: $O$ objetivo do presente artigo é abordar, de forma clara e objetiva, a realidade que passa o direito fundamental à Educação Infantil de qualidade frente à evolução legislativa nos últimos trinta anos após a Constituição Federal de 1988. Para tanto se utilizou de pesquisa documental, legislações nacionais e por meio de pesquisa bibliográficas. Com o desenvolvimento do artigo é possível notar a enorme importância do direito fundamental à Educação Infantil, por suas influências na qualidade de vida como um todo, no entanto, restará claro também que, mesmo diante de tamanha importância, o Estado não tem agido de modo compatível, justificando-se na falta de verba. Ainda, analisa-se o percurso das leis, destacando os desafios no sentido da garantia do direito educacional de forma universal, para todos. Ao longo do trabalho será abordado o direito fundamental à educação, os princípios que o norteiam, suas características e avanços.
\end{abstract}

Palavras-chave: Educação Infantil. Qualidade. Direito. Fundamental. Reserva. Possível.

\section{THE (IN) APPLICABILITY OF THE FUNDAMENTAL RIGHT TO QUALITY CHILD EDUCATION}

\begin{abstract}
The objective of this article is to address, in a clear and objective way, the trajectory that passes the fundamental right to high quality child education in front of the legislative evolution in the last thirty years after the Federal Constitution of 1988. For this purpose we used documentary research, national legislation and through bibliographic research. With the development of the article, it is possible to note the enormous importance of the fundamental right to early childhood education, due to its influences on the quality of life as a whole, however, it will also be clear that, even in the face of such importance, the State has not acted justified by the lack of funds. Also, the course of the laws is analyzed, highlighting the challenges in the sense of guaranteeing the educational right universally, for all. Throughout the work will be approached the fundamental right to education, the principles that guide it, its characteristics and advances.
\end{abstract}

Keywords: Education. Right. Fundamental. Reserve. Possible.

\section{LA (IN)APLICABILIDAD DEL DERECHO FUNDAMENTAL A LA EDUCACIÓN INFANTIL DE CALIDAD}

\begin{abstract}
Resumen: El objetivo de este artículo es abordar, de manera clara y objetiva, la realidad que se convierte en el derecho fundamental a la educación infantil de calidad frente a la evolución legislativa en los últimos treinta años después de la Constitución Federal de 1988. Para tanto se utilizó de la investigación documental, la legislación nacional y a través de investigación bibliográfica. Con el desarrollo del artículo, es posible observar la enorme importancia del derecho fundamental a la educación Infantil, a través de su influencia en la calidad de vida como un todo, sin embargo, evidente que, mismo delante de tal importancia, el Esta do no ha actuado de manera coherente, justificando la falta de recursos. Por fin, se analiza el curso de leyes, destacando los retos para garantizar el derecho de forma universal, la educación para todos. A lo largo de los trabajos abordarán el derecho fundamental a la educación, los principios que la rigen, sus características y sus avances.
\end{abstract}

Palabras-clave: Educación Infantil. Calidad. Derecho. Fundamental. Reserva. Posible.

\section{Introdução}

A aplicabilidade das normas constitucionais no tocante à Educação Infantil tem sido postergada pelas condições socioeconômicas do nosso país, com estrutura ideológica no aspecto da universalização das vagas e principalmente ao tratarmos da qualidade de ensino.

\footnotetext{
${ }^{1}$ Uma versão similar deste texto foi apresentada e publicado nos Anais do VI Simpósio Nacional de Educação na Unioeste - Cascavel no ano de 2018.

${ }^{2}$ Advogada, Pós-graduada em Direito Contemporâneo, Direito Civil e Processo Civil, Professora de Direito do Centro Universitário Univel, aluna regular do Mestrado em Educação pela Universidade Estadual do Oeste do Paraná campus Cascavel. E-mail: anto.neves@ hotmail.com
} 
$\mathrm{O}$ avanço legislativo contrapondo a grande dificuldade de encontrar vagas em creches $\mathrm{e}$ ensino de qualidade, demonstra que ainda se caminha na construção de uma norma efetiva. A Constituição Federal, neste ano de 2018, comemora seus trinta anos de história, a referida Carta Magna elencou em seu artigo $6^{\circ}$ os direitos sociais, prestações positivas que dependem do Estado para serem efetivadas e objetivam garantir a todos o mínimo necessário para que se tenha uma vida digna. São direitos fundamentais de segunda dimensão sem os quais não seria possível garantir a dignidade humana (NOVELINO, 2011).

A efetivação de tais direitos ocorre mediante políticas públicas, as quais visam diminuir a desigualdade social e garantir a existência digna do ser humano. Todos são destinatários dos direitos sociais, embora aqueles que mais necessitam da implementação estatal sejam os hipossuficientes (NOVELINO, 2011).

Dentre os direitos elencados pelo artigo $6^{\circ}$ se encontra o direito à educação, que tem caráter fundamental e uma enorme importância para a formação do indivíduo, e ao ser prestado com qualidade se mostra uma ferramenta de transformação social. Previsto no artigo 205 da Constituição Federal, este princípio pode ser considerado uma prerrogativa para a efetivação dos demais direitos sociais e construção da cidadania (SAVELI; TENREIRO, 2012).

No entanto, como dito anteriormente, os direitos sociais, e aqui se insere a educação, dependem de prestações positivas da administração pública, e não raras vezes o Estado alega a teoria da reserva possível como um motivo da não garantia do direito à educação básica da forma como deveria (SILVA, 2011).

Esta teoria é utilizada pela administração para fundamentar a impossibilidade de efetivar alguma política pública por falta de verbas, como por exemplo, quando não há vagas para alunos nas escolas públicas, isso pode ser exigido pelo administrado e o Estado alega não ter fundos para garantir o direito pleiteado.

Várias são as decisões que impõem ao Poder Executivo que seja garantido o direito fundamental, consequentemente, não dando efetividade à teoria da reserva do possível, utilizada pela administração como argumento para não implementar políticas públicas.

Embora ainda existam algumas decisões aplicando a prevalência da teoria da reserva do possível, é notória a atuação do Poder Judiciário em favor do direito fundamental à Educação Infantil.

Não poderia ser diferente disso, haja vista a enorme importância que exerce o direito fundamental à Educação Infantil na sociedade.

\section{O direito fundamental à educação: Breve abordagem sobre os direitos sociais}


Importante se faz abordar, ainda que de maneira não aprofundada, por não ser este o objetivo específico do presente, os direitos sociais, considerando ser a educação um direito fundamental social.

Os direitos sociais, previstos nos artigos $6^{\circ}$ e seguintes da Constituição Federal, dependem de uma prestação positiva do Estado para serem efetivados, ou seja, dependem que determinada dotação orçamentária esteja disponível e que o Estado se empenhe no sentido de efetivá-los (SILVA, 2009).

Têm como finalidade reduzir as desigualdades sociais, proporcionando uma vida digna para todos, ou seja, pode-se dizer que os direitos sociais são requisitos mínimos para que a sociedade como um todo tenha uma qualidade de vida justa.

Para tanto, tais direitos devem ser fornecidos com qualidade e da maneira como estabelece a constituição, no entanto, o que se observa na realidade não é a qualidade que se espera, mas, sim, descaso com os direitos sociais.

Embora todos sejam destinatários desses direitos, os mais dependentes das prestações do Estado são os hipossuficientes, considerando o fato de que, aqueles que gozam de uma condição financeira mais favorável, via de regra, buscam alternativas privadas, como instituições de ensino particular, hospitais particulares, dentre outras situações (NOVELINO, 2011).

Ingo Wolfgang Sarlet (2013, p. 542) tratando do assunto, assegura que:

Em princípio, toda pessoa pode ser titular de direitos sociais, que não significa a inexistência de restrições, como aquelas impostas em função de específicas condições do titular do direito (caso dos direitos dos trabalhadores, dirigidos a determinado grupo de pessoas) ou em decorrência de condicionamentos fáticos e jurídicos contrapostos à eficácia dos próprios direitos sociais (caso da limitação da gratuidade de prestações apenas às pessoas comprovadamente carentes). De modo geral, porém, vige o princípio da universalidade, pelo qual se fundamenta a extensão dos direitos fundamentais a todas as pessoas, na condição de seres humanos que são [...].

José Afonso da Silva entende que os direitos sociais estão ligados ao direito de igualdade, o autor ainda argumenta que os direitos sociais:

Valem como pressupostos do gozo dos direitos individuais na medida em que criam condições materiais mais propícias ao auferimento da igualdade real, o que, por sua vez, proporciona condição mais compatível com o exercício efetivo da liberdade. (SILVA, 2009, p. 287).

Devido a grande importância que têm os direitos sociais, haja vista o seu conteúdo totalmente voltado para melhorar a condição de vida de todos os cidadãos, estes podem ser protegidos contra qualquer ato estatal tendente a aboli-los ou diminuí-los, nesse sentido: 
Em termos de proteção dos direitos sociais, ou seja, no que diz com as garantias dos direitos sociais contra ingerências por parte de atores públicos e privados, importa salientar que tanto a doutrina quanto, ainda que muito paulatinamente, também a jurisprudência vêm reconhecendo a vigência, como garantia constitucional implícita, do princípio da vedação de retrocesso social, a coibir medidas de cunho retrocessivo por parte do legislador, que, pela revogação ou alteração da legislação infraconstitucional (apenas para citar uma forma de intervenção nos direitos sociais), venha a desconstituir ou afetar gravemente o grau de concretização já atribuído a determinado direito fundamental (e social), o que equivaleria a uma violação a própria CF (SARLET, 2013, p. 542).

Desse modo, fica claro que os direitos sociais, para serem efetivados, dependem de uma prestação positiva do Estado e objetivam garantir a dignidade humana. À educação, como direito fundamental social, aplica-se tudo o que foi dito.

\section{Princípios inerentes ao direito à Educação}

A Constituição Federal de 1988, em seu art. 206, aponta quais princípios devem ser observados no que tange ao direito fundamental à educação, “(...) esse dispositivo constitucional é de fundamental importância na compreensão dos elementos básicos que regem a educação escolar" (MALISKA, 2013, p. 27). Nesse sentido, veja-se:

Art. 206. O ensino será ministrado com base nos seguintes princípios:

I - igualdade de condições para o acesso e permanência na escola;

II - liberdade de aprender, ensinar, pesquisar e divulgar o pensamento, a arte e o saber;

III - pluralismo de idéias e de concepções pedagógicas, e coexistência de instituições públicas e privadas de ensino;

IV - gratuidade do ensino público em estabelecimentos oficiais;

V - valorização dos profissionais da educação escolar, garantidos, na forma da lei, planos de carreira, com ingresso exclusivamente por concurso público de provas e títulos, aos das redes públicas;

VI - gestão democrática do ensino público, na forma da lei;

VII - garantia de padrão de qualidade.

VIII - piso salarial profissional nacional para os profissionais da educação escolar pública, nos termos de lei federal. (BRASIL, Constituição Federal, 1988, art. 206).

Como se vê, são oito os princípios que norteiam o direito à educação, sendo necessário que se faça uma análise, com o objetivo de se fornecer um melhor entendimento a respeito do tema aqui trabalhado.

O Princípio da Igualdade de Condições para o acesso e permanência na escola visa assegurar que todos os brasileiros devem ser tratados de maneira igualitária, sendo inadmissível que se estabeleçam critérios que, de qualquer forma, caracterize a preferência de um aluno sobre outro (BRADBURY, 2015). 
Deve-se atentar para o fato de que essa igualdade abstrata é relativizada pelas diferenças fáticas existentes no plano real, ou seja, aqueles indivíduos que exigirem, por suas condições, um tratamento diferenciado para ter o mesmo acesso à educação, deverão ser atendidos em suas necessidades, nesse sentido:

[...] o acesso e a permanência na escola devem ser vistos sob a perspectiva das diferenças, e isso significa, por exemplo, que o acesso de pessoas com deficiência física aos prédios deve ser garantido mediante rampas de acesso, que o indígena tem o direito de utilizar-se da sua língua materna e dos seus processos próprios de aprendizagem no ensino fundamental, que a identificação de elementos de discriminação que acabam por impedir o acesso e a permanência de grupos na Universidade merecem tratamento diferenciado, enfim, que sem desprestigiar o tratamento isonômico, os elementos de caráter não pessoal que possuem fundamento constitucional, aqui o direito à diferença $\mathrm{e}$ o direito ao pluralismo devem ser levados em conta (MALISKA, 2013, p. 1966).

A igualdade de condições deve ser valorizada, não deixando de lado as diferenças, a fim de que prevaleça a justiça e todos tenha acesso à educação de qualidade.

Com relação ao princípio previsto no inciso II do artigo 206 da Constituição Federal, qual seja o da liberdade de aprender, ensinar, pesquisar e divulgar o pensamento, a arte e o saber, percebe-se claramente que com este princípio se busca dar autonomia aos professores e aos alunos na troca de informações que envolvem o ato de ensinar.

No que se refere ao princípio do pluralismo de ideias e de concepções pedagógicas, e coexistência de instituições públicas e privadas de ensino, podemos dizer que, quanto ao pluralismo de ideias e de concepções, este se encontra inserido no princípio da liberdade de ensinar e divulgar o pensamento, isso porque tal ideal de diversidade já vem protegida pela liberdade (MALISKA, 2013).

Nas palavras de Maliska (2013, p.1967):

São diversos os aspectos que envolvem o princípio do pluralismo, desde o reconhecimento das diferenças regionais e sociais, disposto no $\operatorname{art.} 3^{\circ}$ da Constituição, passando pelas garantias do ensino religioso facultativo e das línguas indígenas maternas do ensino fundamental, constantes do art. $210, \S 1^{\circ} \mathrm{e}$ $2^{\circ}$ da Constituição, e a formação do povo brasileiro, especialmente das matrizes indígena, africana e europeia, conforme dispõem os arts. $26, \S 4^{\circ}$ e $26-\mathrm{A}$ da Lei de Diretrizes e Bases da Educação.

No que diz respeito à coexistência de instituições públicas e privadas, é possível enxergar nesta previsão, mesmo que não seja o real objetivo visado pelo legislador constituinte, uma grande via de descongestionamento do ensino público e, de certo modo, uma relação com o conflito do direito à educação com a teoria da reserva do possível. 
Diz-se isso porque, caso não houvesse instituições privadas de ensino, o Estado teria que promover a educação pública, além das crianças que já a utilizam, para aquelas que utilizam o ensino privado.

Ou seja, o problema seria ainda maior, portanto, é essencial que existam instituições privadas de Educação Infantil e que aqueles que têm condições, matriculem seus filhos nelas, para assim dar oportunidade para aqueles de fato precisam, pois, como já dito, os que mais necessitam da implementação dos direitos sociais são os hipossuficientes.

Além disso, deve-se ressaltar que as instituições privadas são fiscalizadas pelo poder público e devem respeitar os princípios constitucionais a ela aplicáveis, no entanto, isso não impede que, dentro dos limites constitucionais, ela inove em métodos pedagógicos, de modo a contribuir com o pluralismo (MALISKA, 2013).

O princípio da gratuidade do ensino público em estabelecimentos oficiais vislumbra que o Estado em o dever de, gratuitamente, fornecer educação para todos, deve ter dotação orçamentária para tanto, e o que se denota na realidade fática é justamente a falta dela.

De acordo com Marcos Augusto Maliska (2013, p.1968):

A gratuidade, entendida em sentido mais amplo, pode compreender a abstenção de pagamento de mensalidades e de quaisquer despesas, como também uma prestação por parte do Estado. No primeiro caso a Constituição estende a gratuidade a todos os níveis de ensino ofertados pelo Estado, fundamental médio ou superior. Situação diversa apresenta-se quando a gratuidade é entendida como prestação, pois se trata das condições que o Estado deve colocar a disposição dos alunos para que estes desempenhem com êxito as tarefas escolares.

Ou seja, entendida como uma prestação do Estado, não basta que simplesmente a educação seja gratuita, mas para que esta seja ofertada com qualidade deve ser fornecido todo o aporte necessário para que, principalmente, as crianças consigam desenvolver as suas capacidades de maneira adequada, isso quer dizer que o Estado deve fornecer material didático escolar, transporte, alimentação e assistência à saúde, dentre outros fatores que se fizerem necessários.

Princípio importantíssimo é o da valorização dos profissionais da educação escolar, que, por óbvio, também tem íntima ligação com o empecilho da teoria da reserva do possível, tendo em vista que, para garantir a dignidade dos professores é preciso, primeiramente que lhe seja pago um salário digno, bem como que lhe sejam proporcionadas condições adequadas de trabalho.

Maliska (2013, p.1968) afirma, com sabedoria, que: 
Nenhuma sociedade se desenvolve se o profissional da educação não é prestigiado, incentivado e motivado a desempenhar o seu mister dando o melhor de si. O futuro do país e o destino das próximas gerações dependem desse profissional, que desempenha uma função de importância inquestionável (MALISKA, 2013, p.1968).

A importância do profissional da educação de fato é inquestionável, no entanto, sabe-se que o referido princípio não tem sido respeitado como deveria, de modo que o direito à educação é quem sai prejudicado, pois um professor desmotivado não consegue alcançar o seu objetivo.

O princípio da gestão democrática do ensino público tem o objetivo de aproximar a sociedade da instituição de ensino, sempre na intenção de garantir uma melhor educação para as crianças, oportunizando a todos que contribuam com esse objetivo (MALISKA, 2013).

No que se refere ao princípio da garantia de padrão de qualidade, nota-se que dois deveres distintos podem ser extraídos: um dever da escola de prestar o ensino com qualidade e outro dever de fiscalização por parte do Estado. Este princípio também tem estreita relação com a teoria da reserva do possível, haja vista a clara necessidade do investimento de verbas governamentais para que a qualidade seja possível de ser alcançada.

Maliska (2013, p.1968) afirma ainda que:

Ambas as situações geram um direito ao aluno de exigir uma educação escolar de qualidade, com professores capacitados e qualificados, bibliotecas e laboratórios equipados, enfim, o direito de acesso aos meios necessários para que o processo educativo obtenha êxito (MALISKA, 2013, p.1968).

Infelizmente, é de conhecimento geral que ainda hoje, em muitas escolas no Brasil a qualidade da educação é precária, por diversos motivos que não cabe aqui explanar. Alguns estados têm conseguido atingir certa qualidade, no entanto, ainda falta muito para que uma educação realmente de qualidade atinja a todos.

No que diz respeito ao princípio do piso salarial profissional nacional para os profissionais da educação escolar pública, acredita-se que esteja inserido no princípio da valorização dos profissionais da educação, mas vem com o objetivo de asseverar que o professor deve ser valorizado, devendo receber um salário condizente com a fundamental tarefa que exerce.

Concluindo este tópico, importante notar que, todos os princípios educacionais têm certa relação com o tema aqui abordado, qual seja, o direito à Educação Infantil de qualidade e seu avanço legal, alguns menos, outros mais, mas todos podem remeter a este problema.

De maneira geral, relativamente a todos os princípios acima apresentados, importante destacar que, no direito à educação, assim como em todos os aspectos da sociedade, bem como 
no âmbito jurídico, deve ser observada a igualdade material, embasada naquilo que dispõe a igualdade formal.

Ou seja, não se pode desconsiderar os aspectos fáticos da realidade social, devendo-se tratar os iguais com igualdade e os desiguais na medida de sua desigualdade, para que assim, ocorra a justiça.

\section{A característica fundamental do direito à Educação Infantil}

Kant (1999, p. 15) já dizia que "o homem não pode se tornar um verdadeiro homem senão pela educação. Ele é aquilo que a educação dele faz”.

$\mathrm{O}$ direito fundamental à educação está previsto no artigo $6^{\circ}$ da Constituição Federal ao lado dos demais direitos sociais, sendo assim, é conclusão lógica que o direito à educação, para ser efetivado, depende de uma prestação do Estado.

É direito de todos e dever do Estado prestá-lo com qualidade, é o que está previsto no artigo 205 do mesmo ordenamento e nos artigos seguintes são apresentados os princípios inerentes a este direito fundamental (o que foi abordado no tópico anterior), bem como demais diretrizes.

Sendo assim, é evidente a relevância do direito à educação, principalmente a infantil, visto a grande importância que a Constituição Federal deu a este direito, ficando claro que através de uma educação de qualidade, o indivíduo alcança uma vida digna.

Cabe aqui uma breve análise do artigo 205 da Constituição Federal, que em seus próprios elementos deixa clara a característica fundamental do direito à educação.

Primeiro quanto ao pleno desenvolvimento da pessoa, entende-se que se trata de conferir à criança a consciência moral e intelectual:

Quanto ao preparo para o exercício da cidadania, pretende-se por meio do direito à educação, formar cidadãos, capazes de praticarem os atos inerentes à convivência em uma sociedade democrática, nesse sentido, Marcos Augusto Maliska (2013, p. 1965) ressalta alguns fatores interessantes:

Poder-se-ia dizer que a educação (i) é um instrumento permanente de aperfeiçoamento humanístico da sociedade; (ii) promove a autonomia do indivíduo; (iii) promove a visão de mundo das pessoas, a forma como elas vão ver os acontecimentos na sua cidade, no seu país e no mundo. Ela deve ter a função de superadora das concepções de mundo marcadas pela intolerância, pelo preconceito, pela discriminação, pela análise não crítica dos acontecimentos; (iv) promove o sentimento de responsabilidade nas pessoas para com o mundo que vive, o sentimento de que o mundo que está a sua volta é um pouco resultado de suas próprias ações; (v) promove a consciência de que viver em uma República não implica apenas desfrutar direitos, mas também 
compreende responsabilidades cívicas e (vi) promove a consciência pelo valor dos direitos individuais e sociais.

Diante de tudo isso, é incontestável a importância de uma educação de qualidade que atinja todas as crianças, objetivando formar cidadãos capazes de contribuir para a melhoria da sociedade em que vivem, em todos os aspectos possíveis.

Ademais, quanto à qualificação para o trabalho, tal aspecto será melhor trabalhado a seguir, mas diga-se desde logo que "a educação é elemento indispensável ao preparo profissional, quanto mais nos dias atuais, em que o preparo intelectual razoável do trabalhador é julgado como elemento indispensável até mesmo para a realização de tarefas consideradas como trabalho não intelectual” (MALISKA, 2013, p. 1966).

Além disso, a educação encontra amparo também na Declaração Universal Dos Direitos Humanos, especificamente em seu artigo 26:

1.Toda a pessoa tem direito à educação. A educação deve ser gratuita, pelo menos a correspondente ao ensino elementar fundamental. O ensino elementar é obrigatório. O ensino técnico e profissional dever ser generalizado; o acesso aos estudos superiores deve estar aberto a todos em plena igualdade, em função do seu mérito.

2.A educação deve visar à plena expansão da personalidade humana e ao reforço dos direitos do Homem e das liberdades fundamentais e deve favorecer a compreensão, a tolerância e a amizade entre todas as nações e todos os grupos raciais ou religiosos, bem como o desenvolvimento das actividades das Nações Unidas para a manutenção da paz.

3.Aos pais pertence a prioridade do direito de escholher o género de educação a dar aos filhos.

Isso só demonstra que o direito à Educação Infantil é de fundamental importância, de modo que se trata nada menos do que um direito humano universal, reforçando ainda mais a ideia de que, por meio da educação, o indivíduo alcança a emancipação social.

A educação, e aqui nos interessa a infantil, além de ser um direito da criança que pode ser exigido quanto não prestado pelo Estado, é também uma obrigação. Ou seja, a criança não pode se abster de frequentar a escola, isso demonstra a importância desse direito, que diferente dos demais, não é opcional.

A Educação Infantil é a base, ela abre portas para a efetivação dos demais direitos sociais, além disso, pode ser a solução para a violência, baixo desenvolvimento econômico e desigualdades sociais (VIANA; CESAR, 2009).

Sabe-se que a educação cumpre papel importante também quando se trata da preparação e qualificação para o mercado de trabalho, no entanto, deve-se cuidar para que o ensino não seja apenas uma ferramenta para preparar mão de obra, mas sim que seja um meio para fazer crescer, no âmbito da Educação Infantil, um pensamento crítico desde logo nas crianças. 
Isso só tem a contribuir com a sociedade como um todo, tendo em vista que crianças que desde cedo são instigadas a pensar de maneira crítica e buscar soluções práticas para problemas reais, serão adultos mais preparados de um modo geral.

Os autores, dessa vez alertando para o risco de a educação servir de mera ferramenta para qualificação de mão de obra:

Entretanto, é imperioso frisar que a educação não pode, em momento algum, servir de instrumento para a merda qualificação da mão de obra necessária ao desenvolvimento dos setores produtivos, seja no setor industrial ou qualquer outro. E essa é uma das razões que alertam para o fato de que a educação deve ser vista, sempre, a partir do seu caráter amplo e transformador, ultrapassando a mera formação de mão de obra. A educação deve ultrapassar o caráter de reprodução e de manutenção das relações sociais tais quais estão estabelecidas (COSTA; REIS, 2011, p. 388).

Embora a preparação para o mercado de trabalho seja de extrema importância, de modo que este é o caminho para que o indivíduo tenha garantido os demais direitos sociais, é importante que a educação não seja vista apenas com este enfoque, principalmente a infantil, que é a base da criança e irá influenciar em toda a sua formação.

De acordo com Garcia e Ribeiro (2013, p. 637.), a educação deve ser entendida como um “(...) direito social essencial em seu significado e em sua tarefa de construção de uma nova cidadania que respeite o indivíduo sob um viés mais solidário de projeto político-estatal".

Por meio da educação o sujeito alcança a emancipação, é que o afirmam Costa e Reis, em passagem que merece ser citada:

É necessário, portanto, considerar que a educação cumpre um papel fundamental para a emancipação do sujeito e, desse modo, para assegurar o exercício dos seus direitos e deveres fundamentais. Um homem sem educação é um homem alijado de uma parcela significativa de sua existência, sem a qual o exercício pleno de seus direitos fica comprometido (COSTA; REIS, 2011, p. 376).

O direito à Educação Infantil, quando amplamente efetivado e prestado com qualidade se converte em um mecanismo de redução das desigualdades e discriminações (CURY, 2002).

Visando efetivar as mudanças sociais supracitadas, no plano infraconstitucional, a Lei $\mathrm{n}^{\circ}$ 9.394/1996 alterada em 2016, estabeleceu as diretrizes e bases da educação, trazendo, assim como a Constituição, princípios inerentes à educação.

Estar o direito à educação previsto na Constituição Federal em seu artigo $6^{\circ}$, faz dele um direito social fundamental, pressuposto para garantir a dignidade humana, tal reconhecimento dá fundamento para aquele que se vê prejudicado busque a tutela jurisdicional (CURY, 2009). 
Desse modo, fica evidente a característica fundamental do direito à Educação Infantil, tendo em vista a ampla proteção que recebe da Carta Magna, bem como pela existência de lei própria prevendo suas diretrizes e bases, além da irrefutável importância para o desenvolvimento como um todo da pessoa.

\section{Da (in)aplicabilidade dos direitos fundamentais: Reserva do possível e direito fundamental à Educação Infantil}

A aplicabilidade das normas constitucionais no tocante aos direitos à Educação Infantil destaca a importância de priorização da Educação Infantil para desenvolvimento social, histórico e cultural. No entanto, depara-se com dificuldades que os administrados vêm enfrentando na obtenção de vagas e cumprimento da norma.

A positivação constitucional de um direito, como a Educação Infantil, é essencial para provocar uma mudança do discurso jurídico e das práticas sociais, mas por si só não garante a efetivação direito.

Ainda são insipientes as políticas públicas nessa área, além da omissão do Estado na execução daquelas já fixadas, que não satisfazem, suficientemente, a demanda da sociedade.

A educação tem o caráter emancipatório, assim como a saúde tem o fator de promoção da dignidade. Essa ideia foi vislumbrada por Amartya Sen, o Prêmio Nobel da Economia de 1998, que mencionou:

A expansão dos serviços de saúde, educação, seguridade social etc. contribui diretamente para a qualidade da vida e seu florescimento. Há evidencias até de que, mesmo com renda relativamente baixa um pais que garante serviços de saúde e educação a todos pode efetivamente obter resultados notáveis de duração e qualidade de vida de toda população. (SEN, 2010, p.170).

Dessa forma, a lei para nós ainda é vista como autoridade, limite, o descumprimento da norma vislumbra uma violência social. Aspectos históricos e teóricos do problema no contexto brasileiro demonstram a influência, demasiada da imposição legislativa, que tratou a evolução histórica da educação, que por vezes apontou a legislação como norte de mudanças, porem não se pode prever a eficiência nem a eficácia dessas normas.

No que tange a legislação específica da educação, impondo educação de qualidade, esta "qualidade", carregada na norma poderia ser individualizada dentro das aptidões, carências e subjetividade de cada individuo dentro do seu meio.

A lei de forma impositiva, acaba por moldar o indivíduo para o inserir na sociedade, sem adentrar na subjetividade de cada um, particularidades, dificuldades que diferem cada um entre os diferentes meios históricos, culturais e sociais de cada sujeito. Questionável, se realmente é 
possível garantir de forma generalizada um "padrão" de educação de qualidade, com idade e método já pré-estabelecidos de forma genérica?

O sistema influência agressivamente nas imposições legislativas, a sociedade exterioriza a intenção de tornar todos iguais, planificação da existência e o abismo encontrado nessa tentativa.

Analisando a Educação Infantil, já nos deparamos com essa distância, entre o que a lei determina e a realidade vivida, como por exemplo, a lei determina a idade correta para inserir a criança na escola, a necessidade de manutenção de vagas à todos, a realidade é a falta de vagas, falta de verbas, carência financeira, e o Estado acaba por não cumprir regulamentos e normas por inviabilidade do total cumprimento.

Assim temos um embate: Direito Fundamental a Educação Infantil em face da Teoria da Reserva do Possível. Aquele que não tem o seu direito garantido pode ingressar com ação judicial, com o fim de efetivá-lo. O cenário atual em nosso país tem demonstrado, a cada dia mais, uma grande incidência de ações nesse sentido no poder judiciário, principalmente com relação a Educação Infantil (BRADBURY, 2015).

A Teoria da Reserva do Possível é alegada pelo Estado quando está diante de uma política pública prestacional que não pode ser efetivada por escassez de recursos.

A reserva do possível deve ser analisada por três dimensões: quanto a disponibilidade fática; disponibilidade jurídica e quanto a razoabilidade e proporcionalidade da prestação (SARLET, 2007).

Por disponibilidade fática se entende que, não se pode exigir do Estado uma prestação que não possa alcançar a todos, nesse contexto, visa-se respeitar o princípio da isonomia, no sentido de que, se não for possível ao Estado, com a verba disponível, tratar a todos que estejam na mesma situação de maneira isonômica, não pode ele disponibilizar recursos apenas para um caso específico. Nas palavras de Marcelo Novelino (2011, p. 531):

Nesse sentido, não se poderia exigir judicialmente do Estado uma prestação que não pudesse ser concedida a todos o que se encontrem na mesma situação, tendo em vista que o princípio da isonomia exige o mesmo tratamento aos que estejam em situação idêntica. De fato, não parece plausível o entendimento de que a disponibilidade de recursos deva ser analisada apenas em um caso específico, sem levar em consideração outras demandas igualmente legítimas.

Disponibilidade jurídica está atrelada ao princípio da legalidade da despesa, sendo necessário que exista autorização orçamentária para cumprir aquilo que está sendo exigido judicialmente do Estado, para tanto, deve-se analisar a disponibilidade de recursos materiais e humanos. Novelino (2011, p.531) abordou o tema da seguinte forma: 
A disponibilidade jurídica está relacionada à existência de autorização orçamentária para cobrir as despesas exigidas judicialmente do Estado (princípio da legalidade da despesa). Neste caso, deve-se analisar a disponibilidade de recursos materiais e humanos, levando em consideração a distribuição das receitas e competências tributárias, orçamentárias, legislativas e administrativas, as quais deverão ser equacionadas com o sistema federativo brasileiro.

Além disso, é preciso se atentar para a proporcionalidade da prestação e para a razoabilidade do que está sendo exigido. Os dois elementos devem estar cumulativamente presentes para que seja possível a realização da prestação. A pretensão individual/social deve ser razoável em face da disponibilidade financeira estatal para ser despendida na efetivação da política pública (NOVELINO, 2011).

Ademais, ressalta-se que a reserva do possível pode ser alegada pelo Estado como defesa processual, devendo provar de maneira satisfatória a impossibilidade de implementar a prestação que está se exigindo.

Tendo bem delineados o direito fundamental à educação e a sua grande importância, bem como esclarecido do que se trata a teoria da reserva do possível, passa-se à análise conjunta das duas figuras.

\section{Conclusão}

Considera-se que o presente artigo atingiu o seu objetivo, pois elucidou aquilo que se pretendia, ou seja, a existência de um conflito entre o direito à Educação Infantil e a sua aplicação fática face à teoria da reserva do possível adotada pelo Estado.

Tal estudo se faz importante diante da grande importância que o direito à educação exerce na sociedade, de modo que, quando garantido com a devida qualidade, se mostra uma ferramenta de transformação social.

Acredita-se que a teoria da reserva do possível não deva ser sempre desprezada, no entanto, do modo como vem sendo utilizada, foge do seu real objetivo e acaba se tornando uma teoria falaciosa utilizada de modo genérico pela administração pública.

Diferente disso deveriam os governantes trabalhar para diminuir a incidência dessa teoria, com vistas a efetivar o direito à Educação Infantil, sempre buscando melhorias.

Foi possível evidenciar também que este problema tão sério não será resolvido de uma hora pra outra, dependendo de medidas em longo prazo, de modo que a atuação do judiciário muitas vezes pode agravar o problema ao invés de melhorar. 
No entanto, somente assim é que tem sido possível buscar a efetivação do referido direito quando não ofertado, devendo o judiciário atuar sempre para garantir o direito à Educação Infantil, e não contra ele.

Isso porque, se as decisões do judiciário fossem favoráveis à reserva do possível, o município (por se tratar de Educação Infantil) não se sentiria pressionado a buscar mudanças, sendo que este se tornou um meio de pressionar o governo para que atue em favor dos cidadãos.

Por fim, ainda que pareça óbvio, a solução para o problema do direito à Educação Infantil em face da teoria da reserva do possível é um maior investimento orçamentário destinado a esse fim, valorizando os profissionais da educação, proporcionando uma infraestrutura adequada e que suporte o número de crianças que utilizam, para assim, todos receberem educação de qualidade.

\section{Referências}

BRADBURY, Leonardo Cacau Santos La. Direito à Educação: Judicialização, Políticas Públicas e Efetividade do Direito Fundamental. Curitiba: Juruá, 2015.

BRASIL. Constituição (1988). Constituição da República Federativa do Brasil. Brasília, DF: Senado Federal: Centro Gráfico, 2013.

BRASIL. Lei $n^{\circ}$ 9.394, de 20 de dezembro de 1996. Brasília, DF, 20 dez. 1996. Disponível em: <http://www.planalto.gov.br/ccivil_03/leis/19394.htm>. Acesso em: 17 mar. 2015.

COSTA, Marli Marlene Moraes da; REIS, Suzéte da Silva. Educação e Trabalho: Pressupostos da inclusão social e da cidadania no Brasil. Reflexões e Dimensões do Direito: uma cooperação entre Brasil e Espanha. Curitiba: Multideia, 2011.

CURY, Carlos Roberto Jamil; FERREIRA, Luiz Antonio Miguel. A Judicialização da Educação. 2009. Disponível em: <http://www.revistajustitia.com.br/artigos/b4783b.pdf>. Acesso em: 20 mar. 2015.

CURY, Carlos Roberto Jamil. Direito à educação: direito à igualdade, direito à diferença. Cadernos de Pesquisa, São Paulo, n.116, jul. 2002. Disponível em: $<\mathrm{http}: / /$ www.scielo.br/scielo.php?script=sci_arttext\&pid=S0100-15742002000200010>. Acesso em: 12 mar. 2015.

GARCIA, Juliano de Leon; RIBEIRO, Cristine Jacques. A educação como um Direito Social: da construção da cidadania aos desafios do neoliberalismo no Brasil. Revista de Estudos Jurídicos e Sociais, Cascavel, v. 2, p. 117-128, 2013.

KANT, Immanuel. Sobre a pedagogia. Piracicaba: Editora Unimep, 1999.

MALISKA, Marcos Augusto. Comentários aos artigos 205 a 214. In: CANOTILHO, José Joaquim Gomes; MENDES, Gilmar Ferreira; SARLET, Ingo Wolfgang; STRECK, Lenio Luiz. (Coords.). Comentários à Constituição do Brasil. São Paulo: Saraiva/Almedina, 2013. p. 19641975.

NOVELINO, Marcelo. Direito Constitucional. Rio de Janeiro: Forense; São Paulo: Método, 2011.

SAVELI, Esmérida de Lourdes; TENREIRO, Maria Odete Vieira. A educação enquanto Direito Social: aspectos históricos e constitucionais. Teoria e Prática da Educação, Maringá, v. 15, n. 2, 
p.51-57, 2012. Disponível em: 〈http://www.dtp.uem.br/rtpe/volumes/v15n2/04.pdf〉. Acesso em: 16 mar. 2015.

SEN, Amartya. Desenvolvimento como liberdade. São Paulo: Companhia das Letras, 2010.

SILVA, Carlos Eduardo Moreira da. Direito à educação em face do princípio da reserva do possível: a importância dos instrumentos de controle social. Jornal de Políticas Educacionais. São Paulo, p. 41-50. jan. 2011. Disponível em: <http://www.jpe.ufpr.br/n9_5.pdf>. Acesso em: 15 mar. 2015.

SILVA, José Afonso da. Curso de Direito Constitucional Positivo. São Paulo: Malheiros, 2009.

VIANA, Mateus Gomes; CESAR, Raquel Coelho. Direito à Educação no Brasil: Exigibilidade Constitucional. 2009.

Disponível em: <http://www.fa7.edu.br/recursos/imagens/File/direito/ic/v_encontro/direitoaeducacaonobrasil.pd f>. Acesso em: 17 mar. 2015. 